\title{
(t)
}

\section{O SERVIÇO SOCIAL DA UNIVERSIDADE DE BRASÍLIA NO COMPASSO DAS DIRETRIZES CURRICULARES}

\author{
The social service of the university of brasilia in compass of the curricular guidelines
}

\author{
Hayeska Costa Barroso* \\ https://orcid.org/0000-0002-8280-7187 \\ Mariléia Goin ${ }^{* *}$ \\ https://orcid.org/0000-0003-4859-3098
}

\begin{abstract}
RESUMO
As Diretrizes Curriculares denotam um marco sócio-histórico e ético no processo formativo em Ser viço Social, na Universidade de Brasília. Desta forma, o presente artigo se propõe a dialogar acerca dos principais eixos constitutivos dos Projetos Pedagógicos do Curso Serviço Social da referida Universidade, ao longo dos seus 50 anos de existência, considerando que as mudanças advindas com as Diretrizes Curriculares se tornam um marco divisor de águas entre as concepções pretéritas e presentes e revelam seu compromisso ético e político assumido no âmbito da categoria. Em suma, as Diretrizes Curriculares foram elementares para delinear a face com que o Serviço Social da UnB viria a se apresentar após o primeiro decênio do século XXI, ao tempo em que consolida sua maturidade e reconhecimento institucional, bem como a histórica participação estratégica do corpo docente, discente e de profissionais egressos/as nas fileiras da organização política, técnica, teórica e acadêmica do Serviço Social brasileiro.
\end{abstract}

\section{PALAVRAS-CHAVE}

Serviço Social. Diretrizes Curriculares. Universidade de Brasília. Formação Profissional.

\section{ABSTRACT}

The Curricular Guidelines denote a socio-historical and ethical framework in the training process in Social Service, at the University of Brasilia. In this way, this article proposes to dialogue about the main constitutive axes of the Pedagogical Projects of the Social Service Course of that University, throughout its 50 years of existence, considering that the changes resulting from the Curriculum Guidelines become a dividing mark of waters between past and present conceptions and reveal their ethical and political commitment assumed within the category. In short, the Curricular Guidelines were elementary to outline the face with which the Social Service of UnB would come to present itself after the first decade of the 21st

\footnotetext{
* Assistente Social. Doutora em Sociologia. Professora Adjunta do Departamento de Serviço Social da Universidade de Brasília (UnB, Brasília (DF), Brasil). Campus Universitário Darcy Ribeiro, Brasília (DF), CEP.: 70910-900. E-mail: hayeska.barroso@unb.br.

${ }^{* *}$ Assistente Social. Pós-Doutora em Serviço Social. Professora Adjunta do Departamento de Serviço Social da Universidade de Brasília. (UnB, Brasília (DF), Brasil). Campus Universitário Darcy Ribeiro, Brasília (DF), CEP.: 70910-900. E-mail:mari.goin84@gmail.com.
}

\section{DOI 10.22422/temporalis.2020v2on40p112-127}

(cc)) EY A(s) Autora(s)/O(s) Autor(es). 2019 Acesso Aberto Esta obra está licenciada sob os termos da Licença Creative Commons Atribuição 4.0 Internacional (https://creativecommons.org/licenses/by/4.o/deed.pt_BR), que permite copiar e redistribuir o material em qualquer suporte ou formato, bem como adaptar, transformar e criar a partir deste material para qualquer fim, mesmo que comercial. O licenciante não pode revogar estes direitos desde que você respeite os termos da licença.

Temporalis, Brasília (DF), ano 20, n. 40, p. 112-127, jul./dez. 2020. | ISSN 2238-1856 


\section{temporalis}

century, while consolidating its maturity and institutional recognition, as well as the historical strategic participation of the body professor, student and professional in the ranks of the Brazilian Social Service's political, technical, theoretical and academic organization.

\section{KEYWORDS}

Social Service. Curricular Guidelines. University of Brasília. Professional Qualification.

\section{NOTAS INTRODUTÓRIAS AO DEBATE}

$\mathrm{P}$ assados quase 25 anos da aprovação das Diretrizes Curriculares pela então ABESS/CEDEPS 1 , é notória que sua orientação formativa não está ilesa a disputas profissionais e tentativas de sufocamento ídeo-político, no bojo de efervescentes polêmicas em torno da sua implementação, de sua operacionalidade e de seu diálogo com a realidade das unidades de formação acadêmica.

Não obstante tais polêmicas, é indispensável afirmar que o pressuposto central das Diretrizes é a organização curricular e de seus conteúdos (teórico-ético-políticosculturais) de forma dinâmica, assegurando a formação profissional com consistência teórico-metodológica, coerência ético-política e competência técnico-operativa para a apreensão crítica: (1) do processo histórico como totalidade; (2) das particularidades da constituição e desenvolvimento do capitalismo e do Serviço Social no país; (3) do significado social da profissão, desvelando as possibilidades de ação contidas na realidade; (4) das demandas - consolidadas e emergentes; e (5) do trabalho profissional a partir das competências e atribuições profissionais (ABEPSS, 1996).

Nessa ótica, as referidas Diretrizes denotam um marco sócio-histórico e ético no processo formativo em Serviço Social na Universidade de Brasília (UnB $)^{2}$, uma vez que os caminhos profissionais traçados no compasso das orientações teórico-metodológicas e éticopolíticas ali dispostas conduzem a concepção de profissão e de perfil profissional explicitamente definido, sem titubeios ou neutralidades infundadas.

Sumariamente, o presente artigo se propõe a dialogar, mesmo que brevemente, acerca dos principais eixos constitutivos dos Projetos Pedagógicos do Serviço Social da referida Universidade, considerando que as mudanças advindas com as Diretrizes Curriculares se tornam um marco divisor de águas entre as concepções pretéritas e presentes e revelam seu compromisso ético e político assumido no âmbito da categoria, especialmente considerando o envolvimento e o protagonismo assumidos ao longo dos seus 50 anos de existência.

\section{O MARCO DAS DIRETRIZES CURRICULARES NA FORMAÇÃO PROFISSIONAL EM SERVIÇO SOCIAL NA UNB}

O Serviço Social, na Universidade de Brasília (UnB), tem seus primeiros registros datados de 1971, quando o déficit financeiro resultante da ausência da inadimplência de discentes

\footnotetext{
${ }^{1}$ Associação Brasileira de Ensino em Serviço Social/Centro de Documentação e Pesquisa em Políticas Sociais e Serviço Social.

${ }^{2}$ A Universidade de Brasília foi criada em 1962, dois anos após a inauguração de Brasília como capital do país.
}

Temporalis, Brasília (DF), ano 20, n. 40, p. 112-127, jul./dez. 2020. | ISSN 2238-1856 


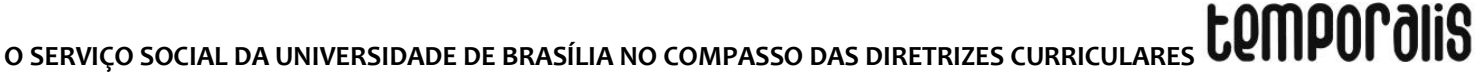

e do repasse governamental comprometeram a continuidade das atividades da então Sociedade Feminina de Instrução e Caridade - instituição fundada, em Brasília, em 1962, para criar o curso de Serviço Social, sem nenhuma vinculação com universidades, públicas ou privadas (PEREIRA, 2009). A - UnB, nesse cenário, cria o curso 3 para absorver discentes regularmente matriculados/as naquela instituição católica, com ampla tradição no ensino de Serviço Social, ao passo que computava sete escolas em território brasileiro, distribuídas em diferentes estados.

O currículo de 1970, à época baseado no currículo mínimo aprovado pelo Conselho Federal de Educação para as escolas de Serviço Social, previa a integralização da formação em 8 semestres, totalizando 165 créditos. Destes, destaca-se, além das disciplinas de Serviço Social de Caso, Grupo e Comunidade - oriundas da influência teórico-técnica estadunidense, que se fortalece a partir dos anos $1960 \mathrm{com}$ a laicização da profissão -, a oferta de quatro disciplinas de estágio, entre $05^{\circ}$ e $08^{\circ}$ semestre, que somados totalizavam 47 créditos e, aproximadamente, $30 \%$ da carga horária total do curso. Destaca-se, ainda, a presença de quatro disciplinas de Teoria do Serviço Social $\left(2^{\circ}\right.$, $3^{\circ}, 4^{a}$ e $8^{\circ}$ semestres), que refletiam inspiração organizacional didática e curricular na fragmentária teoria positivista, cujo divisionismo e mecanicismo prevaleciam em detrimento da razão dialética, distanciando-se, tão logo, da relação com o método e com os processos sociais que conduziram a profissão no decorrer do seu processo sóciohistórico.

Prevalece nessa disposição curricular o enquadramento em disciplinas isoladas, priorizando o trato teoricista, “[...] entendido como a apropriação idealista do real, em que a transmissão de conteúdos teóricos basta para o domínio de sólido referencial teórico, em face da centralidade teórica em detrimento do seu diálogo fecundo com a realidade social [...]" (GOIN, 2019b, p. 9-10), bem como a ênfase metodologista, cujo debate privilegia a definição de um modelo de intervenção e o ensino das técnicas e dos instrumentos, ilustradas por um fabuloso manual operativo de como "fazer Serviço Social". A ausência da concepção de que os fundamentos da dimensão técnico-operativa está alicerçada nas teórico-metodológica e ético-política é notória.

A revisão crítica da tendência expressa na referida formulação curricular ganha tônus nacional a partir da análise do currículo de 1982, quando a síntese de inúmeros eventos e pesquisas realizadas culminam na aprovação, na metade da última década do Século XX, da "Proposta de Currículo Mínimo para o Curso de Serviço Social” pela Assembleia Geral Extraordinária, de 8 de novembro de 1996, no Rio de Janeiro, elaborada pela então ABESS, juntamente com o CEDEPSS, CFESS (Conselho Federal de Serviço Social) e ENESSO (Executiva Nacional de Estudantes de Serviço Social) - as quais, em 1997, são expressas na forma de "Diretrizes Gerais para o Curso de Serviço Social", em face da mudança de nomenclatura atribuída pela nova Lei de Diretrizes e Bases da Educação Nacional, aprovada em dezembro de 1996.

A nova lógica curricular tem como eixo articulador a indissociabilidade entre história, teoria e método, no intento de superar a prevalente tricotomia disposta no pretérito

\footnotetext{
${ }^{3}$ O primeiro reconhecimento do Curso de Serviço Social na Universidade de Brasília se deu por meio do Decreto $n^{\circ} .74 .194$, de 20 de junho de 1974.
}

Temporalis, Brasília (DF), ano 20, n. 40, p. 112-127, jul./dez. 2020. | ISSN 2238-1856 


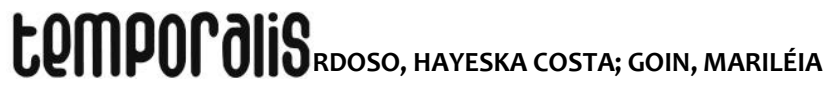

projeto de formação. Esse processo não só inaugura uma nova dinâmica aos conhecimentos elementares à formação e ao trabalho profissional, como também celebra a gênese do que hodiernamente se conhece como Fundamentos do Serviço Social, os quais se encontram ancorados no âmbito de três Núcleos de Fundamentos ${ }^{4}$ Núcleo de Fundamentos Teórico-Metodológicos da Vida Social, Núcleo de Fundamentos da Formação Sócio-Histórica da Sociedade Brasileira e Núcleo de Fundamentos do Trabalho Profissional - que

[...] não se tratam de eixos hierarquizados, classificatórios e autônomos, mas interdependentes e indissociáveis, que expressam níveis diferenciados e complementares de abstração para decifrar a profissão na dinâmica societária e ancoram os Fundamentos do Serviço Social. Aliás, é na articulação que a sua apreensão se torna possível (GOIN, 2019b, p. 2).

No tocante ao Serviço Social da UnB, a revisão curricular para a incorporação das novas orientações dispostas no documento da ABEPSS se dá em consonância com um conjunto de formulações teóricas, didáticas, éticas e jurídico-formais de âmbito nacional e institucional, a exemplo: da (1) Lei de Diretrizes e Bases da Educação Nacional (LDB), Lei n. 9394/1996; da (2) Lei de Regulamentação da Profissão de Assistente Social, Lei $n^{0}$ 8.662, de 7 de junho de 1993; do (3) Código de Ética dos Assistentes Sociais, Resolução CFESS n. 273/93, de 13 de março de 1993 (e suas posteriores alterações); e da (4) Resolução do Conselho de Ensino, Pesquisa e Extensão CEPE/ UnB, n² 219/96, de 18 de dezembro de 1996 (SER/UnB, 2001), e culminará, em 2001, na vigência de um novo projeto de formação profissional.

Os marcos, dessa revisão, estão calcados na XXVIII Convenção da então ABESS, de 1993, realizada em Londrina, cujas deliberações definiram a revisão do currículo mínimo vigente desde 1982 (Parecer CFE n 412, de 04.08.1982 e Resolução nº 06, de 23/09/82), ao passo que a avaliação do processo de formação profissional em Serviço Social dar-se-ia a partir das novas exigências laborais à área, considerando as mudanças conjunturais e as jurídico-formais, internas e externas à profissão, do pós-1980. Nessa esteira, a consolidação na UnB deu-se em três momentos, cada qual com sua devida relevância profissional e institucional: 1) início, em 1994, quando foi nomeada a primeira Comissão de Revisão; 2) entre 1995 e 1996, quando a referida Comissão, ao contar com novos membros, promove a adaptação do currículo em vigência; e 3) após a aprovação da Proposta Básica, em 1996, quando se deliberou pela revisão curricular a partir das orientações dispostas no documento legitimado em convenção, pela agora ABEPSS.

O primeiro momento é iniciado imediatamente após a Convenção que define pela retomada do processo de formação profissional no Brasil em consonância com os desafios interpostos à profissão naquele tempo presente. A Comissão designada para trabalhar na revisão curricular do SER/UnB dedicou-se a identificar os estrangulamentos do currículo em vigor, a partir de sugestões e indicações docentes, discentes e de profissionais da área. O ponto de partida de tais reflexões deu-se com base em indagações de fundo: o perfil que se desejava formar; a dimensão teórico-metodológico do curso; e a operacionalização curricular em face de qual proposta pedagógica. Esse processo resultou na elaboração de um documento preliminar denominado "Proposta de

\footnotetext{
${ }^{4}$ Para maiores informações sobre tais Núcleos, consultar item 3 das Diretrizes da ABEPSS de 1996.
} 


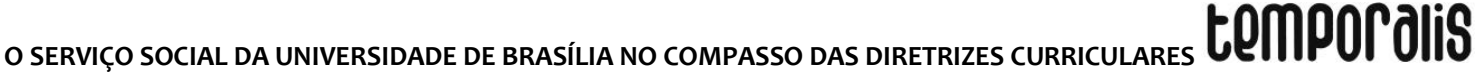

Reforma Curricular da UnB" - elementar mencionar que, após discussões realizadas no âmbito das oficinas promovidas em todo o país, muitas das contribuições dispostas nesse documento preliminar foram incorporadas no documento da ABESS, aprovado pela XXIX Convenção, em 1995, em Recife, doravante denominado "Proposta Básica" (SER/UnB, 2001).

O segundo momento, por sua vez, tão fundamental quanto o primeiro, dá continuidade ao que fora iniciado em 1993 e promove adaptações curriculares que atingiram, principalmente, as disciplinas Teoria Geral do Serviço Social 1, 2 e 3 e Metodologia do Serviço Social 1,2 e 3, na medida em que o movimento delineava a incorporação conceitual dos Fundamentos do Serviço Social a partir da incidência teórico-metodológico de cariz onto-crítico e que implicava na apreensão indissolúvel da unidade entre história, teoria e método. Após esforços da comissão envolvida no processo de revisão, em 1996, foi aprovada a "Proposta de Reforma Curricular" e enviada à ABESS, como contribuição institucional ao debate nacional (SER/UnB, 2001). O documento da entidade nacional foi aprimorado com a contribuição de consultores da área e, em 1996, em Assembleia Extraordinária, teve aprovada a elaboração da sua versão final, que contou com a ampla participação e contribuição de unidades acadêmicas filiadas. Todavia, imediatamente após sua aprovação - precisamente um mês depois - é aprovada a nova LDB, que aderiu ao termo Diretrizes Curriculares em substituição ao então denominado Currículo Mínimo. Reunindo esforços junto às unidades de ensino participantes para a preservação da proposta, a ABEPSS enviou para a Secretaria de Educação Superior, do Ministério da Educação (MEC/SESU), em 1997, a versão das "Diretrizes Gerais para o Curso de Serviço Social”, para análise e aprovação.

Nessa esteira, o terceiro momento de revisão do SER/UnB, que não finaliza, mas consolida o movimento iniciado ainda no primeiro quartel da última década do Século XX, promoveu esforços para a implantação do novo currículo, com base no documento final aprovado em 1996, considerando as particularidades do Curso na UnB e sua interlocução com o debate nacional. É elementar destacar, nesse bojo, que professores do Departamento de Serviço Social assumiram a diretoria executiva da ABEPSS, em dezembro de 1998, e isso provocou a necessidade de: (1) fortalecer a proposta nacional e (2) reconsiderar elementos da proposta da UnB aprovada em meados de 1996. A constituição de uma proposta que atendesse às demandas institucionais e contemplasse a proposta nacional "[...] esbarrava nas reais condições de trabalho dos professores do SER, com a sobrecarga de atividades, a renovação do quadro docente e o esvaziamento do quadro ocasionado pelas aposentadorias e pela política governamental de suspensão de concursos públicos para a universidade" (SER/UnB, 2001, p. 7). Em meio a essas condições adversas, a versão final da revisão foi aprovada pela instância máxima de deliberação do Departamento - o Colegiado do SER - no ano 2000, para então ser encaminhado para a aprovação institucional, que passou a vigorar a partir de 2001, com a equivalência (entre matérias básicas e disciplinas) ${ }^{5}$ indicada na Tabela 1, a seguir.

\footnotetext{
${ }^{5}$ As matérias básicas “[...] são expressões de áreas de conhecimento necessárias à formação profissional [...]” (ABEPSS, 1996, p. 15) que se desdobram pedagogicamente em um conjunto de componentes que ganham forma didática em disciplinas, seminários temáticos, oficinas, atividades complementares, estágio supervisionado, trabalho de conclusão de curso e outros componentes curriculares.
}

Temporalis, Brasília (DF), ano 20, n. 40, p. 112-127, jul./dez. 2020. | ISSN 2238-1856 
Tabela 1 - Equivalência entre as "matérias básicas" dispostas nas Diretrizes da ABEPSS e o novo Currículo do SER/UnB (2001)

\begin{tabular}{|c|c|}
\hline Matérias Básicas das Diretrizes Curriculares & Disciplinas do Currículo SER/UnB (2001) \\
\hline Sociologia & $\begin{array}{l}\text { Introdução à Sociologia } \\
\text { Oficina de Teoria Social } 1 \\
\text { Oficina de Teoria Social } 2 \\
\text { Oficina de Teoria Social } 3\end{array}$ \\
\hline Teoria Política & Política Social \\
\hline Economia Política & Introdução à Economia \\
\hline Filosofia & Introdução à Filosofia \\
\hline Psicologia & Introdução à Psicologia \\
\hline Antropologia & Introdução à Antropologia \\
\hline Formação Sócio-histórica do Brasil & $\begin{array}{l}\text { Questão Social e Serviço Social } \\
\text { Fundamentos Históricos e Teórico-Metodológicos do } \\
\text { Serviço Social } 1\end{array}$ \\
\hline Direito e Legislação Social & $\begin{array}{c}\text { Direitos Humanos e Cidadania } \\
\text { Infância, Adolescência e Cidadania } \\
\text { Seguridade Social } 1 \text { - Assistência e Previdência Social } \\
\text { Seguridade Social } 2 \text { - Saúde } \\
\text { Política de Trabalho }\end{array}$ \\
\hline Política Social & $\begin{array}{c}\text { Política Social } \\
\text { Seguridade Social } 1 \text { - Assistência e Previdência Social } \\
\text { Seguridade Social } 2 \text { - Saúde } \\
\text { Infância, Adolescência e Cidadania } \\
\text { Política Habitacional } \\
\text { Política de Educação } \\
\text { Política de Trabalho }\end{array}$ \\
\hline Desenvolvimento Capitalista e Questão Social & Questão Social e Serviço Social \\
\hline $\begin{array}{l}\text { Fundamentos Históricos e Teórico-Metodológicos } \\
\text { do Serviço Social }\end{array}$ & $\begin{array}{l}\text { Introdução ao Serviço Social } \\
\text { Fundamentos Históricos e Teórico-Metodológicos do } \\
\text { Serviço Social } 1\end{array}$ \\
\hline Trabalho e Sociabilidade & $\begin{array}{c}\text { Trabalho e Sociabilidade } \\
\end{array}$ \\
\hline Serviço Social e Processos de Trabalho & $\begin{array}{c}\text { Processos de Trabalho e Serviço Social } 1 \\
\text { Processos de Trabalho e Serviço Social } 2 \\
\text { Instituições e Práticas Sociais }\end{array}$ \\
\hline Administração e Planejamento em Serviço Social & Planejamento e Administração em Serviço Social \\
\hline Pesquisa em Serviço Social & $\begin{array}{l}\text { Pesquisa em Serviço Social } 1 \\
\text { Pesquisa em Serviço Social } 2 \\
\end{array}$ \\
\hline Ética Profissional & Fundamentos Éticos e Ética Profissional \\
\hline
\end{tabular}

Fonte: SER/UnB (2001, p. 14-15).

Tal equivalência traçou um perfil profissional (1) habilitado a trabalhar com as expressões da "questão social", por meio de políticas sociais; (2) dotado de formação generalista e crítica, com capacidade criativa e propositiva no âmbito dos desafios interpostos pelo mundo do trabalho; e (3) comprometido com os valores e princípios norteadores do Código de Ética do Assistente Social (1993) (SER/UnB, 2001).

Temporalis, Brasília (DF), ano 20, n. 40, p. 112-127, jul./dez. 2020. | ISSN 2238-1856 
o Serviço social da UniVersidade de brasília no compasso das diretrizes curriculares 6010010

A revisão curricular mencionada celebra a incorporação das orientações emitidas pela categoria, no bojo das transformações no processo de produção e reprodução da vida social, elementarmente a partir dos anos 1990, quando determinadas pela contrarreforma do Estado, pelas novas e complexas formas expressas pelo objeto profissional e pelas mudanças na relação entre o público e o privado, as quais demandam um perfil profissional atento às demandas do tempo presente, ciente de que as particularidades que o Serviço Social assume na divisão social e técnica do trabalho "[...] têm estreito eco com a dinamicidade da vida social, galvanizada pelos condicionantes econômicos, políticos e ideológicos expressos sob a órbita do capital" (GOIN, 2019a, p.23).

No âmbito da celebração dos 10 anos das Diretrizes Curriculares da ABEPSS, a realização de pesquisa avaliativa para monitoramento de sua implementação pela gestão 2005-2006 - cujo objetivo foi identificar as condições e tendências nas unidades de ensino que ofertavam o curso a partir de eixos temáticos ${ }^{6}$ - levou ao processo de reflexão departamental na UnB acerca da continuidade da análise do currículo de $2001^{7}$, iniciada com a referida pesquisa.

A metodologia adotada, diferentemente da revisão anterior, distribuiu a comunidade acadêmica envolvida a partir dos três Núcleos de Fundamentos, de modo a identificar as disciplinas respectivas a cada Núcleo, donde derivou a necessidade de mudanças em disciplinas e em seus conteúdos correspondentes, elementarmente nas seguintes: (1) Oficinas de Teoria Social, (2) Fundamentos Históricos e Teórico-Metodológicos do Serviço Social, (3) Questão Social, (4) Processos de Trabalho, (5) Oficina de Instrumental TécnicoOperativo, (6) Pesquisa em Serviço Social, (7) Fundamentos Éticos e Ética Profissional, (8) Estágio $^{8}$, (9) Economia Política e (10) Direito e Legislação Social (SER/UnB, 2011a).

A partir da identificação daqueles que foram considerados "nós críticos", em um segundo momento houve o debruçamento na revisão das referidas disciplinas e centrou-se na compatibilização de ementas, programas e bibliografia, e na adequação de carga horária com o conteúdo previsto. A referida revisão culminou na consolidação do Projeto Pedagógico em vigência, o qual prevê as seguintes disciplinas, apontadas na Tabela 2, de acordo com sua distribuição nos Núcleos de Fundamentação.

\footnotetext{
${ }^{6}$ Constituíram-se como eixos temáticos da pesquisa: "[...] fundamentos históricos e teórico-metodológicos do Serviço Social, trabalho, questão social, pesquisa e o tratamento dispensado à prática na formação profissional; e os dados sobre o perfil das Unidades de Ensino públicas e privadas que participaram do processo investigativo" (ABREU, 2007a, p. 11).

${ }^{7}$ A revisão curricular foi permeada de um cenário grevista, de troca na gestão da reitoria e de adesão ao Programa de Reestruturação e Expansão das Universidades Federais (REUNI), que entre articulações e percalços, postergaram para o primeiro semestre de 2009 a continuidade das discussões iniciada anos antes.

${ }^{8}$ Considerando a incorporação das orientações dispostas na Resolução do CFESS n.533/08 e na Lei de Estágios, n.11.788/08.
} 
Tabela 2 - Distribuição das disciplinas nos Núcleos de Fundamentação na revisão de 2011

\begin{tabular}{|c|c|}
\hline Núcleos de Fundamentação & Disciplinas obrigatórias vinculadas ao Núcleo \\
\hline $\begin{array}{l}\text { Núcleo de Fundamentos Teórico-Metodológicos } \\
\text { da Vida Social }\end{array}$ & $\begin{array}{c}\text { Introdução a Sociologia } \\
\text { Economia Política e Capitalismo } \\
\text { Teoria Sociológica I } \\
\text { Política Social } \\
\text { Introdução a filosofia } \\
\text { Introdução a Psicologia } \\
\text { Introdução a Antropologia } \\
\text { Questão social e Serviço Social } \\
\text { Trabalho e sociabilidade } \\
\end{array}$ \\
\hline $\begin{array}{l}\text { Núcleo de Fundamentos da Formação Sócio- } \\
\text { Histórica da Sociedade Brasileira }\end{array}$ & $\begin{array}{c}\text { Introdução ao Serviço Social: } \\
\text { Questão social e Serviço Social: } \\
\text { Movimentos sociais } \\
\text { Fundamentos históricos e teórico-metodológicos } \\
\text { do Serviço Social I } \\
\text { Fundamentos históricos e teórico-metodológicos } \\
\text { do Serviço Social II } \\
\text { Fundamentos históricos e teórico-metodológicos } \\
\text { do Serviço Social III }\end{array}$ \\
\hline Núcleo de Fundamentos do Trabalho Profissional & $\begin{array}{c}\text { Introdução ao Serviço Social } \\
\text { Questão social e Serviço Social } \\
\text { Fundamentos históricos e teórico-metodológicos } \\
\text { do Serviço Social I } \\
\text { Fundamentos históricos e teórico-metodológicos } \\
\text { do Serviço Social II } \\
\text { Fundamentos históricos e teórico-metodológicos } \\
\text { do Serviço Social III } \\
\text { Trabalho e Sociabilidade } \\
\text { Processos de Trabalho e Serviço Social I } \\
\text { Processos de Trabalho e Serviço Social II } \\
\text { Seguridade Social I } \\
\text { Seguridade Social II } \\
\text { Seguridade Social III } \\
\text { Pesquisa social I } \\
\text { Pesquisa social II } \\
\text { Estágio em Serviço Social I } \\
\text { Estágio em Serviço Social II } \\
\text { Fundamentos Éticos e Ética profissional } \\
\text { Planejamento, Administração e Gestão Social }\end{array}$ \\
\hline
\end{tabular}

Fonte: Síntese elaborada pelas autoras, a partir de SER/UnB (2011a; 2011b).

Sustentadas no âmbito dos Núcleos de Fundamentação, tais disciplinas contemplam um projeto de formação consistente, que se reverbera: (1) na concepção de profissão; (2) no perfil profissional que se deseja formar; (3) no lugar do estágio nesse processo e na sua correspondente supervisão; (4) no diálogo entre as dimensões formativas, sem escamotear seu aparato democrático e articulado; e (5) nas atividades complementares ao processo formativo, seja em termos de pesquisa, seja em extensão. Como lembra Guerra (2018), a premissa que orienta o projeto de formação coerentemente se atrela a um projeto de profissão, que claramente defende que Serviço Social, seus objetivos, suas atribuições e competências, suas respostas profissionais às demandas da realidade presente e suas possibilidades de novas respostas às tradicionais requisições institucionais. 
o SerViço social da uniVersidade de brasília no compasso das diretrizes curriculares 6010010

Foi sintonizada no bojo das exigências profissionais contemporâneas que a revisão solidificada em 2011 teve como objetivo

Consolidar uma formação profissional de caráter generalista e crítica, com sólido embasamento teórico-metodológico, ético-político e técnico-operativo que possibilite ao futuro assistente social a apreensão do significado social da profissão, a compreensão dos desafios impostos pela realidade social e a capacidade de materializar as possibilidades de ação nela contidas (SER/UnB, 2011a, p. 16).

Nessa via de análise, é indiscutível que as Diretrizes Curriculares da ABEPSS ${ }^{9}$ reiteram as escolhas teórico-metodológica e ético-política pautadas em uma perspectiva (ontodialética) que, antes de tudo, é um modo de ver a vida; é movimento e provisoriedade; é negação permanente dos estados, ao passo que o instituído pode ser (sempre) superado; é contradição, sendo este o motor que está na base da luta de classes; é multicausal, processual e histórico, que ignora a unicausalidade e as determinações pré-concebidas; é avessa à neutralidade, ao pressupor que sempre há tomada de posição - afinal, não posicionar-se é um posicionamento. A formação, assim, é o processo síntese que ininterruptamente gera novas sínteses provisórias, pois cada tese oriunda de sucessivas aproximações - movimento de investigação e mediação teórico-prática - será negada para chegar a novas sínteses provisórias (MENDES; PRATES, 2007).

A considerar os princípios das Diretrizes relativos aos fundamentos da formação profissional, sobretudo no que tange à superação da fragmentação de conteúdos na organização curricular e o seu caráter interdisciplinar (ABEPSS, 1996), a revisão curricular que subsidiou o novo Projeto Político Pedagógico do Curso de Serviço Social na UnB garantiu, dentre outros aspectos, a interface de disciplinas em mais de um dos eixos dos Núcleos de Fundamentação, haja vista que "[...] a formação profissional constitui-se de uma totalidade de conhecimentos que estão expressos nestes três núcleos, contextualizados historicamente e manifestos em suas particularidades" (ABEPSS, 1996, p. 8). Reconhece, portanto, e não somente, a transversalidade do conteúdo de cada núcleo, mas também avança na direção de uma formação baseada na apreensão da totalidade como elemento indispensável para desvelar as contradições inerentes às relações de produção e reprodução da vida social como um marco no bojo de comemoração dos seus 50 anos na UnB.

\section{ANOS DO SERVIÇO SOCIAL NA UNB: PROTAGONISMO E LEGADO INSTITUCIONAL}

O Departamento de Serviço Social da UnB chega aos seus 50 anos com a composição docente formada por 32 professores/as efetivos, dos/as quais 29 doutores/as e 3 mestres ( 2 com doutorado em andamento), 2 professores/as visitantes e 1 professor/a em exercício provisório. Vinculado ao SER, tem-se o Programa de Pós-Graduação em Política Social (PPGPS) $)^{10}$, o qual conta com 14 professores/as do SER em seu corpo docente permanente. Além disso, parte desses/as professores/as capilariza-se institucionalmente,

\footnotetext{
${ }^{9}$ Entende-se que as Diretrizes aprovadas pelo MEC, em 2002, esvaziam o debate ídeo-político imerso nas Diretrizes da ABEPSS.

${ }^{10}$ O PPGPS foi criado em 1990, a partir da implantação do mestrado. Em 2002, foi criado o doutorado. Tratase de uma pós-graduação de notável reconhecimento nacional e internacional, avaliada com conceito 6 pela Coordenação de Aperfeiçoamento de Pessoal de Nível Superior (CAPES).
}

Temporalis, Brasília (DF), ano 20, n. 40, p. 112-127, jul./dez. 2020. | ISSN 2238-1856 


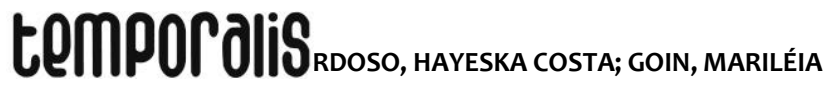

contribuindo em diversos programas de pós-graduação da universidade, de modo a reforçar a interdisciplinaridade e o caráter generalista e pluralista da profissão.

\begin{abstract}
O pluralismo, aqui, considerado como aspecto constitutivo da natureza da vida acadêmica, portanto uma exigência do processo de formação, sob a orientação do projeto ético-político profissional que se concretiza no embate e debate entre as diferentes correntes de pensamento e da ação humana, com a prevalência e direção da Teoria Social crítica (ABREU, 2007b, p.121).
\end{abstract}

No âmbito da dinâmica institucional universitária, este mesmo corpo docente já ocupou posições de destaque no campo da gestão, ao assumir a direção de decanatos e institutos, assim como em comissões e comitês institucionais. É histórica e efetiva, também, a participação do Serviço Social da UnB nas entidades representativas da categoria docente e nas entidades organizativas da profissão, como a ABEPSS e o conjunto CFESS/CRESS.

As disciplinas optativas de "Prática de Pesquisa"11, com o objetivo de garantir o "desenvolvimento da atitude investigativa e do desenvolvimento de pesquisas"

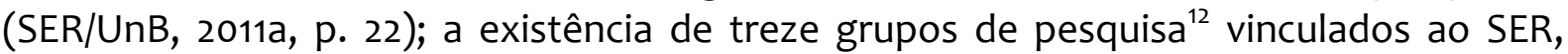
certificados pelo Diretório dos Grupos de Pesquisa no Brasil, do Conselho Nacional de Desenvolvimento Científico e Tecnológico (CNPq); e a sólida pós-graduação, podem ser considerados indicadores do lugar da pesquisa no Serviço Social da UnB, ratificando um dos princípios que fundamentam a formação profissional, conforme as Diretrizes Curriculares de 1996, ou seja, o "[...] estabelecimento das dimensões investigativa e interventiva como princípios formativos e condição central da formação profissional, e da relação teoria e realidade" (ABEPSS, 1996, p. 6).

Na esteira do debate sobre a produção de conhecimento nos cursos de graduação em Serviço Social da UnB (diurno e noturno), segundo a Biblioteca Digital da Produção Intelectual Discente da Universidade de Brasília, entre o ano de 1995 e julho de $2017^{13}$, foram apresentados 759 trabalhos de conclusão de curso (TCCs), os quais são considerados um requisito curricular para a obtenção do diploma na graduação (ABEPSS, 1996), podendo se constituir “[...] em trabalho de sistematização teórica da experiência decorrente do estágio ou análise teórico-crítica decorrente de investigação de um problema de pesquisa" (SER/UnB, 2011a, p. 33). A partir do ano de 2006, o SER estabeleceu diretrizes gerais para PTCC $^{14}$ e TCC, em que definiu, sobretudo, as competências e as atribuições de coordenadores de curso, docentes e discentes.

\footnotetext{
${ }^{11}$ As disciplinas optativas de Prática de Pesquisa I, II, III e IV “[...] propicia[m] a inserção em projetos de pesquisa, em núcleos e grupos de estudos e pesquisa consolidando a atitude investigativa" (SER/UnB, 2011a, p.28; SER/UnB, 2011b, p.17).

${ }^{12}$ Informação disponível em:

http://www.politicasocial.unb.br/index.php?option=com_content\&view=article\&id=13\&ltemid=653. Acesso em: 10 abr. 2020.

${ }^{13}$ A Biblioteca Digital da Produção Intelectual Discente da Universidade de Brasília não disponibiliza online as informações dos anos anteriores.

${ }^{14}$ O Projeto de Trabalho de Conclusão de Curso (PTCC) é pré-requisito para o TCC e pode ser considerado o início do processo de orientação. Trata-se de disciplina obrigatória, com carga horária de 60 horas e 4 créditos cada.
}

Temporalis, Brasília (DF), ano 20, n. 40, p. 112-127, jul./dez. 2020. | ISSN 2238-1856 
Segundo o Anuário Estatístico da UnB (UNB, 2019), o curso de Serviço Social possuía 645 alunos regularmente matriculados no segundo semestre de 2018, dos quais 311 no curso diurno e 334 no curso noturno. Desde a sua criação, em 1971, O SER formou 1.177 assistentes sociais (DPO/UnB, 2019b) $)^{15}$ - deste total, 154 são egressos do curso noturno ${ }^{16}$, criado exatamente num contexto em que se operava: o processo de revisão do currículo de 2001; a ampliação da demanda por assistentes sociais no campo profissional (SER/UnB, 2011b); e a expansão do ensino público superior federal a partir do REUNI. Para tanto,

[...] a adesão ao REUNI considerou uma antiga demanda de criação do curso noturno para atender trabalhadores/estudantes e reivindicou junto às instâncias superiores da UnB as condições adequadas para a ampliação do Departamento, preservando e melhorando a qualidade tanto do curso diurno como do noturno, em processo de criação. A contratação de mais docentes para o Departamento de Serviço Social - SER, a formação de um corpo docente qualificado e integrado, e ampliação do espaço físico do departamento, foram as principais condições requeridas (SER/UnB, 2011b, p. 4, grifos nossos).

Em consonância com o que prevê as Diretrizes Curriculares de 1996, uma das principais preocupações nesse movimento de criação do curso noturno foi a garantia de manutenção dos "[...] padrões de qualidade [...] sem caracterizar um distanciamento do curso diurno, garantindo suas particularidades" (SER/UnB, 2011b, p. 4), e quatro horas/aulas diárias, no máximo, de atividades (ABEPSS, 1996). A criação de cursos noturnos no ensino superior público significa, em síntese, a abertura do acesso à universidade para segmentos da população historicamente destituídos, minimamente, da possibilidade de ingresso, dadas as condições objetivas de vida e de trabalho para a classe-que-vive-do-trabalho (ANTUNES, 2002), para quem o ensino superior se apresenta como possibilidade de ascensão social e aumento de status social na configuração familiar (IAMAMOTO, 2014). Reitera-se, desse modo, que

A construção coletiva de proposta de formação acadêmica no Serviço Social norteia-se pela defesa da universidade pública, gratuita e de qualidade, direcionada aos interesses da coletividade e enraizada na realidade regional e nacional; a universidade que cultiva razão crítica e o compromisso com valores universais, coerente com sua função pública, não limitada e submetida a interesses particulares exclusivos de determinadas classes ou frações de classes; uma instituição a serviço da coletividade, que incorpore os dilemas regionais e nacionais como matéria da vida acadêmica, participando da construção de respostas aos mesmos no âmbito de suas atribuições (IAMAMOTO, 2014, p. 625).

Os fluxos curriculares dos cursos diurno e noturno, para tanto, diferenciam-se na quantidade de semestres previstos para a conclusão da graduação: 8 semestres no diurno e 10 semestres no noturno (SER/UnB, 2011a, 2011b). Dados mais recentes produzidos pelo Relatório AvaliaUnB (DPO/UnB, 2019), contudo, indicam uma tendência: o tempo médio de conclusão do curso, desde o ingresso até a formatura, no diurno tem sido superior em 1 semestre em relação ao fluxo curricular, ou seja, os/as discentes do diurno terminam o curso em 9 semestres, ao passo que os/as do noturno seguem o fluxo curricular previsto no Projeto Político Pedagógico, que é de 10 semestres. Outra informação relevante está relacionada ao tempo médio de evasão que, no noturno, é de três semestres, e no diurno

\footnotetext{
${ }^{15}$ Conforme o Relatório AvaliaUnB (2019a), são considerados/as formados/as todos/as discentes da UnB que concluíram o curso, por formatura em graduação, até o ano de 2018.

${ }^{16} \mathrm{O}$ curso de Serviço Social noturno da Universidade de Brasília foi o primeiro curso criado no turno da noite numa Instituição de Ensino Superior (IES) no Distrito Federal (DF).
}

Temporalis, Brasília (DF), ano 20, n. 40, p. 112-127, jul./dez. 2020. | ISSN 2238-1856 


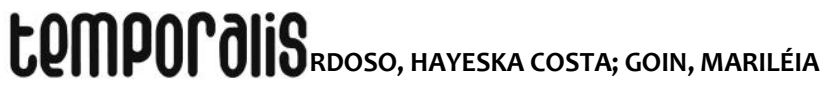

de quatro semestres, o que significa dizer que os/as discentes do noturno evadem mais cedo.

Dentre as formas de ingresso no Curso de Serviço Social, na UnB, dentre outras, destacam-se duas modalidades: o Programa de Avaliação Seriada (PAS) ${ }^{17}$ e o vestibular tradicional. O primeiro foi responsável pelo ingresso de 155 discentes no curso diurno e 20 no noturno do total de formados/as desde a criação do curso; pela via do vestibular tradicional 715 ingressaram no curso diurno e 123 no noturno.

Na formação profissional em Serviço Social, o estágio, uma das atividades indispensáveis integradoras do currículo (ABEPSS, 1996), é considerado uma atividade curricular obrigatória, que se materializa a partir da inserção discente em um espaço sócioocupacional, sob supervisão direta e sistemática, com o objetivo de capacitá-lo para o trabalho profissional (ABEPSS, 1996; SER/UnB, 2011a, 2011b, 2018).

O estágio se constitui num instrumento fundamental na formação da análise crítica e da capacidade interventiva, propositiva e investigativa do(a) estudante, que precisa apreender os elementos concretos que constituem a realidade social capitalista e suas contradições, de modo a intervir, posteriormente como profissional, nas diferentes expressões da questão social (ABEPSS, 2009, p. 11).

Desde 1982, o Departamento de Serviço Social da UnB tem demonstrado preocupação com a regulamentação interna do estágio, quando, àquele ano, elaborou o Manual de Estágio do Departamento de Serviço Social, em sintonia com a proposta de currículo mínimo e as demandas pela realidade da profissão no Brasil (SER/UnB, 2018). Em 1999, foi criado o Fórum de Supervisão de Estágio da UnB, espaço que ocupou lugar central desde estão em relação às discussões fundamentais relacionadas ao estágio no curso. A revisão curricular, que resultou na revisão de 2001, inclusive, contou com a contribuição dos debates empreendidos no Fórum, sistematizados por uma comissão específica. No ano seguinte à sua criação, o Fórum elaborou as "Diretrizes para Estágio Supervisionado" (2000), atualizado nove anos depois como um "Manual de Estágio da UnB” (2009).

Ainda em relação ao estágio, a revisão curricular operada em 2011 na UnB esteve respaldada nos seguintes dispositivos legais: Resolução CFESS N ${ }^{\circ} 273 / 1993$, que institui o Código de Ética Profissional dos Assistentes Sociais; Lei № 8.662/1993, que regulamenta a profissão de assistente social; Lei de Diretrizes e Bases da Educação, de 1996; Lei № 11.788/2008, conhecida como "Lei do Estágio" que dispõe sobre o estágio obrigatório e não obrigatório; Resolução CNE/CES N 492/2001, que estabelece as Diretrizes para o curso de Serviço Social pelo Ministério da Educação; Resolução CFESS No 533/2008, que regulamenta a supervisão direta de estágio no Serviço Social; e Política Nacional de Estágio da ABEPSS, de 2009 (SER/UnB, 2011a, 2011b).

A carga horária do estágio obrigatório no SER equivale a $16 \%$ do total do curso, atendendo à orientação das Diretrizes Curriculares que indicam que a carga horária mínima do estágio supervisionado deve corresponder a, pelo menos, 15\% da carga horária mínima do

\footnotetext{
${ }^{17}$ O PAS da UnB é um programa pioneiro, que consiste em um processo seletivo realizado ao longo dos três anos do ensino médio regular. Em 2020, o Programa completa 25 anos e metade das vagas em todos os cursos da universidade é destinada para discentes aprovados/as no Programa.
}

Temporalis, Brasília (DF), ano 20, n. 40, p. 112-127, jul./dez. 2020. | ISSN 2238-1856 
o SERVIÇo social da uniVersidade de brasília no compasso das diRetrizes curriculares 6010070

curso. São, portanto, 480 horas, divididas em duas disciplinas de $16 \operatorname{créditos}^{18}$, com 240 horas cada uma, das quais 210 horas sob supervisão de campo e 30 horas sob supervisão acadêmica ${ }^{19}$. Além da modalidade do estágio obrigatório, o Projeto Político Pedagógico de 2011 (SER/UnB, 2011a, 2011b) avança ao incluir a supervisão acadêmica de estágio não obrigatório, reconhecido enquanto tal desde a Lei $N^{\circ} 11.788 / 2008$. A referida supervisão passou a ser realizada por meio de duas disciplinas optativas ${ }^{20}$ de 2 créditos - Oficina de Estágio 1 e Oficina de Estágio 2 - cada uma com 60 horas.

O Projeto Político Pedagógico do SER de 2011 também enfatizou a importância de que sua implementação esteja sintonizada com o Projeto Pedagógico Institucional (PPI) e com o Plano de Desenvolvimento Institucional (PPI) da UnB. Apontou, ainda, a necessidade de se elaborar mecanismos de acompanhamento de egressos/as e sua consequente inserção no mercado de trabalho.

Sintonizado com as Diretrizes Curriculares, o currículo de 2011 reconhece que a formação profissional implica capacitação teórico-metodológica, ético-política e técnico-operativa capaz de permitir ao/a assistente social inserido/a nos espaços sócio-ocupacionais

[...] apreender criticamente o processo histórico como totalidade; compreender as particularidades da constituição e do desenvolvimento histórico da sociedade brasileira e do Serviço Social no país; reconhecer o significado social da profissão e desvelar as possibilidades de ação contidas na realidade; identificar as demandas - consolidadas e emergentes - dirigidas ao Serviço Social e formular respostas profissionais capazes de enfrentar a questão social, considerando as articulações entre público e privado (SER/UnB, 2011a, p.17-18).

A UnB, no ano de 2013, estabeleceu convênio com o Ministério do Trabalho e Emprego (MTE), a fim de acessar as informações da Relação Anual de Informações Sociais (RAIS), as quais possibilitaram "[...] uma série de levantamentos sobre a atuação dos ex-alunos da UnB” (DPO/UNB, 2019b, p. 1). A identificação dos/as egressos do curso de Serviço Social da UnB obedeceu a dois critérios: 1) discentes que ingressaram na UnB e saíram de seus cursos, por formatura ou evasão, até o ano de 2017; e 2) presentes na RAIS 2017. 775 ex-discentes do curso de Serviço Social estavam presentes no banco de dados da RAIS de 2017, dos quais um pouco mais da metade (381, mais precisamente) atuava na área da "Administração Pública, Defesa e Seguridade Social”, conforme a Classificação Nacional de Atividades Econômicas (CNAE). Do universo de egressos/as considerado, é possível

\footnotetext{
${ }^{18}$ Estágio em Serviço Social 1 e Estágio em Serviço Social 2.

${ }^{19}$ Semestralmente são ofertadas 12 turmas de estágio supervisionado obrigatório no SER, obedecendo a seguinte distribuição: 3 turmas diurnas de Estágio em Serviço Social 1, 3 turmas noturnas de Estágio em Serviço Social 1, 3 turmas diurnas de Estágio em Serviço Social 2 e 3 turmas noturnas de Estágio em Serviço Social 2. Além disso, são ofertadas 1 turma de Oficina de Estágio 1 e 1 turma de Oficina de Estágio 2, ambas optativas.

${ }^{20}$ Os alunos só podem se matricular nas disciplinas optativas de Oficina de Estágio depois de terem sido aprovados nas disciplinas de estágio obrigatório. Logo, o Projeto Político Pedagógico não prevê, em consonância com a legislação vigente, a realização de estágio não-obrigatório sem o cumprimento dos devidos pré-requisitos das disciplinas que abordam os conteúdos relacionados à ética profissional e fundamentos histórico-teórico-metodológicos do Serviço Social (ABEPSS, 2010) que, no caso do SER são: (1) Fundamentos Éticos e Ética Profissional, e (2) Fundamentos Históricos, Teóricos e Metodológicos 3. "Dessa forma, o estágio não-obrigatório do curso de Serviço Social da UnB deve ser desenvolvido nos semestres finais do curso, a partir do desdobramento das disciplinas e de seus competentes curriculares" (SER/UnB, 2011a, 2011b).
}

Temporalis, Brasília (DF), ano 20, n. 40, p. 112-127, jul./dez. 2020. | ISSN 2238-1856 


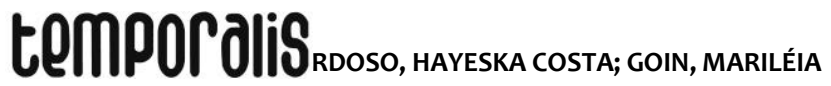

afirmar que: $87 \%$ trabalham no Distrito Federal; os homens formados ganham, em média, $8 \%$ a mais do que as mulheres formadas; e a remuneração dos servidores públicos efetivos formados é, em média, $111 \%$ maior do que a remuneração dos/as empregados/as CLT formados/as. Quanto à natureza do vínculo empregatício, ratificando a premissa de que o "Estado, nos diversos níveis da federação, é [ainda] hoje o maior empregador dos assistentes sociais, e a atuação na órbita das políticas públicas um espaço profissional privilegiado desse profissional" (IAMAMOTO, 2014, p. 611), verifica-se que 66\% estão no serviço público efetivo, $30 \%$ são celetistas, 3\% estão no serviço público não-efetivo e $2 \%$ possuem vínculo temporário/avulso.

Diante das questões aludidas, é inegável o reconhecimento do lugar que as Diretrizes Curriculares de 1996 ocupam na constituição da histórica identidade do Serviço Social na UnB, marcada notadamente pela qualidade de uma formação profissional de cariz crítico, técnico, teórico e político. Para além da história do curso de graduação, a ênfase aqui recai sobre as condições conjunturais e estruturais que o instituíram, atravessadas pelo desvelamento dos processos sociais que permeiam a constituição histórica do Serviço Social como profissão, inserido na divisão social e técnica do trabalho, no bojo das relações de produção e reprodução social.

\section{À GUISA DE TOTALIZAÇÃO, SEMPRE PROVISÓRIA}

A centralidade do projeto profissional crítico, a capacidade desse projeto erigir as bases ideo-políticas do Serviço Social como profissão, mas também de catalizar processos coletivos no âmbito da organização dos sujeitos enquanto categoria e de processos crítico-reflexivos em torno daquilo que, não somente é objeto da profissão, mas é também seu fundamento histórico, teórico e metodológico, são os principais indicadores de uma formação e de um trabalho profissionais forjados nas bases de uma história que foi além dos próprios muros e que conseguiu se ressignificar no "[...] jogo das forças sociais" (IAMAMOTO, 2014, p. 622).

Parecem não restar dúvidas, no cenário aludido, do quão elementar as Diretrizes Curriculares foram para delinear a face com que o Serviço Social da UnB viria a se apresentar após o primeiro decênio do século XXI, período no qual se consolida sua maturidade e reconhecimento no campo interno institucional da própria universidade, bem como a participação estratégica do corpo docente, discente e de profissionais egressos/as nas fileiras da organização política, técnica, téorica e acadêmica do Serviço Social brasileiro. O horizonte traçado até ali forjara as bases que constituíram as feições do Serviço Social na UnB indissociadas da identidade da categoria em nível nacional, cujas marcas são indicadoras de seu protagonismo político, nos 80 anos da profissão no Brasil, e institucional, nos seus 50 anos na Universidade de Brasília. Foi partícipe, portanto, de grandes acontecimentos históricos no ensino superior público e no Serviço Social brasileiro, assumindo as trincheiras das lutas sociais em defesa da qualidade da formação profissional e da universalização do ensino superior público, que o Serviço Social da UnB demarca seu compasso não só com as Diretrizes Curriculares da ABEPSS, mas com o conjunto de orientações dispostas em âmbito ético e político profissional. 
o Serviço social da universidade de brasília no compasso das diretrizes curriculares 6010010

\section{AGRADECIMENTOS}

De modo especial, agradecemos a presteza, a solicitude e a contribuição documental das memoráveis professoras no Departamento de Serviço Social da UnB, Profa Dra. Potyara Amazoneida Pereira Pereira, aposentada, e Profa Dra. Carolina Cassia Batista Santos, hoje na Universidade Federal do Amazonas.

\section{REFERÊNCIAS}

ABREU, Marina Maciel. Apresentação. Temporalis, Brasília (DF): Associação Brasileira de Ensino e Pesquisa em Serviço Social, ano 7, n. 14, p. 9-12, jul./dez. 2007 a.

ABREU, Marina Maciel. Pesquisa em Serviço Social: tendências na implantação das Diretrizes Curriculares. Temporalis, (DF): Associação Brasileira de Ensino e Pesquisa em Serviço Social, ano 7, n. 14, jul./dez. 2007b.

ANTUNES, Ricardo. Os Sentidos do Trabalho. 6a ed. São Paulo: Boitempo, 2002.

ASSOCIAÇÃO BRASILEIRA DE ENSINO E PESQUISA EM SERVIÇO SOCIAL (ABEPSS).

Diretrizes gerais para o Curso de Serviço Social (Com base no Currículo Mínimo aprovado em Assembleia Geral Extraordinária de 8 de novembro de 1996). Rio de Janeiro, 1996. Disponível em: http://www.abepss.org.br/arquivos/textos/documento_201603311138166377210.pdf. Acesso em: 7 abr. 2019.

ASSOCIAÇÃO BRASILEIRA DE ENSINO E PESQUISA EM SERVIÇO SOCIAL (ABEPSS). Política Nacional de Estágio da Associação Brasileira de Ensino e Pesquisa em Serviço Social. Brasília (DF), 2010.

DPO/UnB - Decanato de Planejamento, Orçamento e Avaliação Institucional da Universidade de Brasília. Relatório AvaliaUnB (2017-2019). Brasília, $2019 a$.

DPO/UnB - Decanato de Planejamento, Orçamento e Avaliação Institucional da Universidade de Brasília. Egressos Rais - Análise dos egressos da Graduação da UnB do curso de Serviço Social. Brasília, 2019b.

GOIN, Marileia. Fundamentos do Serviço Social na América Latina e no Caribe: conceituação, condicionantes sócio-históricos e particularidades profissionais. Campinas/SP: Papel Social, 2019a.

GOIN, Marileia. Tendências atuais no ensino dos Fundamentos do Serviço Social. Textos \& Contextos, Porto Alegre, v. 18, n. 2, p. 1-12, jul./dez. 2019 b.

GUERRA, Yolanda. Consolidar avanços, superar limites e enfrentar desafios: os Fundamentos de uma formação profissional crítica. In: GUERRA, Yolanda et al. Serviço Social e seus fundamentos: conhecimento e crítica. Campinas/SP: Papel Social, 2018, p. 2546. 
IAMAMOTO, Marilda Villela. A formação acadêmico-profissional no Serviço Social brasileiro. Serviço Social e Sociedade, São Paulo, n. 120, p. 608-639, dezembro de 2014.

MENDES, Jussara Maria Rosa; PRATES, Jane Cruz. Algumas reflexões acerca dos desafios para a consolidação das Diretrizes Curriculares. Temporalis, Brasília (DF): Associação Brasileira de Ensino e Pesquisa em Serviço Social, ano 7, n. 14, p. 175-197, jul./dez. 2007.

PEREIRA, Potyara Amazoneida Pereira. História do curso de Serviço Social da Universidade de Brasília. Serviço Social e Sociedade, São Paulo, n. 97, p. 5-25, jan./mar. 2009.

SER/UnB - Departamento de Serviço Social da Universidade de Brasília. Revisão Curricular do Curso de Graduação em Serviço Social. Brasília (DF), 2001.

SER/UnB - Departamento de Serviço Social da Universidade de Brasília. Projeto Político Pedagógico do Curso de Graduação em Serviço Social Diurno. Brasília (DF), $2011 a$.

SER/UnB - Departamento de Serviço Social da Universidade de Brasília. Projeto Político Pedagógico do Curso de Graduação em Serviço Social Noturno. Brasília (DF), 2011b.

SER/UnB - Departamento de Serviço Social da Universidade de Brasília. Política de Estágio do Curso de Serviço Social da Universidade de Brasília. Brasília (DF), 2018.

UNB - Universidade de Brasília. Anuário Estatístico (2019). Brasília (DF), 2019.

\footnotetext{
Hayeska Costa Barroso Trabalhou concepção e delineamento; análise e interpretação dos dados; redação do artigo, revisão crítica e na aprovação da versão a ser publicada.

Professora Adjunta do Departamento de Serviço Social da Universidade de Brasília - UnB. Assistente Social pela Universidade Estadual do Ceará - UECE. Mestre em Políticas Públicas e Sociedade pela Universidade Estadual do Ceará - UECE. Doutora em Sociologia pela Universidade Federal do Ceará - UFC. Pesquisadora do Grupo de Estudos e Pesquisas sobre Fundamentos do Serviço Social e América Latina - GFAL. Pesquisadora do Observatório da Violência Contra a Mulher - OBSERVEM/UECE.

Mariléia Goin Trabalhou concepção e delineamento; análise e interpretação dos dados; redação do artigo e revisão crítica.

Professora Adjunta do Departamento de Serviço Social da Universidade de Brasília. Assistente Social pela Universidade Regional do Noroeste do Estado do Rio Grande do Sul. Mestre em Serviço Social pela Universidade Federal de Santa Catarina. Doutora em Serviço Social pela Pontifícia Universidade Católica do Rio Grande do Sul. Pós-Doutora em Serviço Social pela Pontifícia Universidade Católica de São Paulo. Líder do Grupo de Estudos e Pesquisas sobre Fundamentos do Serviço Social e América Latina - GFAL.
}

Temporalis, Brasília (DF), ano 20, n. 40, p. 112-127, jul./dez. 2020. | ISSN 2238-1856 